\title{
AIRBORNE PARTICLES POLLUTION IN DEJ CITY
}

\author{
IOAN AUREL CHERECHES ${ }^{a}$, IOAN PETEAN ${ }^{b}$, \\ GERTRUD-ALEXANDRA PALTINEAN ${ }^{\mathrm{b}, ~}{ }^{,}$, AURORA MOCANU ${ }^{\mathrm{b}}$, \\ LIANA MURESAN ${ }^{c}$, GEORGE ARGHIR $^{\mathrm{d}}$, MARIA TOMOAIA-COTISEL ${ }^{\mathrm{b}, e}$
}

\begin{abstract}
Environmental data achieved with the Air Quality Monitoring Station in Dej city, Romania, reveal a normal state of particulate matter (PM) emissions below the standard limit in April and May 2017. These airborne particles contain a large amount of mineral fractions such as: quartz, calcite, clays (e.g., kaolinite and muscovite), and lepidocrocite. Their size varies in a wide range: from 1 to $200 \mu \mathrm{m}$ for floating particles (FP) and from 1 to $10 \mu \mathrm{m}$ for PM10 observed by optical microscopy and SEM. The in vivo testing shows the ability of PM10 to penetrate into the upper respiratory tract. Mineral fractions were found in nasal exudates. At a shorter exposure time (e.g., 1 minute), only PM10 particles were observed. Particles larger than PM10 were found in nasal exudates at prolonged exposure for up to 3 minutes.
\end{abstract}

Keywords: Floating particles, PM10, hazard

\section{INTRODUCTION}

Dej is a representative city in Cluj County, Romania, mainly for exploitation of sodium chloride from medieval times. Geological layers are typical for Badenian sediments associated with halite deposits [1-3]. Minerals, such as quartz, calcite, and clays, are the major components of Dej soil. Neglected green spaces are sensitive to decay and dust particles formation [4-6], which can be elevated in the atmosphere under favorable environmental

\footnotetext{
a Technical University of Cluj-Napoca, Faculty of Mechanics, Muncii Ave., No. 103 -105, RO400641 Cluj-Napoca, Romania.

b Babeş-Bolyai University, Faculty of Chemistry and Chemical Engineering, Arany Janos Str., No. 11, RO-400084 Cluj-Napoca, Romania.

c Technical University of Cluj-Napoca, Faculty of Materials and Environment Engineering, Muncii Ave., No. 103 -105, RO-400641 Cluj-Napoca, Romania.

d Technical University of Cluj-Napoca, Faculty of Materials and Environment Engineering, Muncii Ave., No. 103 -105, RO-400641 Cluj-Napoca, Romania.

e Academy of Romanian Scientists, 54 Splaiul Independentei, 050094, Bucharest, Romania.

*Corresponding author: pgertrud@gmail.com
} 
conditions [7-12]. Dry and windy days are the most favorable for the mineral emission in the atmosphere, while the wet ones ensure the fixing of the dust on the soil surfaces.

The first category of pollutant air particles susceptible to being found in Dej city is floating particles (FP), which contain a large amount of mineral classes. These particles are raised in the atmosphere by strong air currents and after a short flight fall down to the soil [13-15]. Such behavior is less harmful for living beings. However the standard limit of FP is $17 \mathrm{~g} / \mathrm{m}^{2} / \mathrm{month}$ [16-18].

PM10 are more dangerous airborne particles for living beings due to their ability to long travel in the atmosphere until their fall to the soil [19-24] with their maximum diameter of $10 \mu \mathrm{m}[25,26]$. Due to their small size, they are easily inhaled in the respiratory system. The penetration capacity depends on the type, shape and size of the particles. The literature data show that minerals, as usual, in Dej city soils can form a very small fraction in the urban environment $[27,28]$. PM10 contains significant amounts of micro particles called PM2.5 [29, 30] and submicron particles, even nano particles grouped in the PM1 and PM0.5 classes [31-34]. Fraction PM1 and nano require special probe techniques [35-40]. Exposure to airborne particles may lead to acute pulmonary and cardiovascular symptoms [41, 42] and for long-term exposure could lead to silicosis and lung cancer [43]. Exposure depends on the breathing manner in days with high PM emissions (windy days). Nasal breathing is more protective than oral due to the ability of the nose mucosa to catch particles from the inhaled air [44].

\section{RESULTS AND DISCUSSION}

The Air Quality Monitoring Station (AQMS) is located in the center of Dej city, at the confluence of the main transport facilities between the urban and industrial nodes around the Somes River Bridge. It refers to airborne particles caused by various sources from soil disintegration, transport, and industrial activities related to the salt and furniture industry. The measured environmental data are centralized in Table 1.

Table 1. PM emission level in Dej city in April and May 2017

\begin{tabular}{|c|c|c|c|}
\hline \multicolumn{2}{|c|}{ Emission type } & April 2017 & May 2017 \\
\hline \multirow{2}{*}{$\begin{array}{c}\mathrm{PM} 10, \\
\mu \mathrm{g} / \mathrm{m}^{3}\end{array}$} & minimum & 6.34 & 2.53 \\
\cline { 2 - 4 } & maximum & 40.79 & 45.32 \\
\cline { 2 - 4 } $\mathrm{FP}$, & average & 21.51 & 19.42 \\
$\mathrm{~g} / \mathrm{m}^{2} / \mathrm{month}$ & downtown & 14.30 & 7.21 \\
\cline { 2 - 4 } & Industrial area & 13.79 & 26.4 \\
\hline
\end{tabular}

PM10 values are below the standard limit in April and May 2017, demonstrating that the atmosphere in Dej city is appropriate for normal life. However, there are two-day records when the weather was dry and windy 
when PM10 emissions are very close to the limit. In these days with wind, the in vivo tests were performed.

The FP emissions are in good parameters for the city downtown in April as well as in May, but for the industrial area the value for May 2017 exceeds the limit of $17 \mathrm{~g} / \mathrm{m}^{2} /$ month. This could result in some accidental inhalation of mineral particles. Therefore, both representative FP and PM10 samples collected with AQMS require a proper physical and chemical characterization.

Figure 1 shows the XRD spectra $(a, c)$ and optical microscopy images ( $b$ and $d$ ) with cross-polarized optical polarization for FP, Figure 1a and Figure 1b, and for PM10, Figure 1c and Figure 1d.

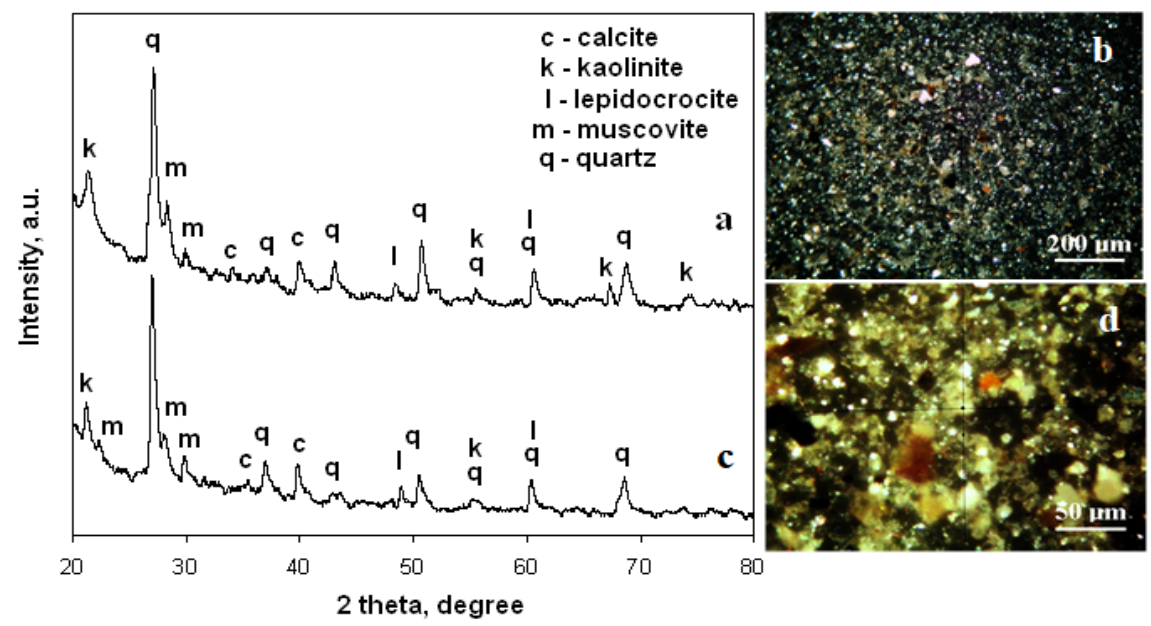

Figure 1. The mineralogical characterization of PM collected from Dej city AQMS. Floating particles: a) XRD spectrum and b) cross polarized light microscopy image;

The PM10: c) XRD spectrum and d) cross polarized light microscopy image.

The XRD spectra have very well-developed, narrow-form peaks that demonstrate the crystallinity of the samples. Dominant mineral is the quartz followed by the clay mixture of kaolinite and muscovite. There is also a significant amount of calcite and traces of lepidocrocite.

The XRD data were correlated with cross-polarized light microscopy to observe the shape and size range for each identified mineral. The data are centralized in Table 2. Quartz is the dominant mineral in all particulate air samples in this investigation. Small and ultra-small fractions are found in FP and PM10 due to fragmentation of silicates $[27,29]$ in the urban environment.

Rounded polyhedral quartz particles are seen in the SEM images, FP of Figure $2 a$, and PM10 in Figure $2 b$. It is to be observed the higher refinement of quartz in PM10 than in the fractions found in FP. These prove to be more dangerous due to their small size and broken parts. 
I. A. CHERECHES, I. PETEAN, G.-A. PALTINEAN, A. MOCANU, L. MURESAN, G. ARGHIR, M. TOMOAIA-COTISEL

Table 2. Properties of minerals identified in FP and PM10 samples

\begin{tabular}{|c|c|c|c|c|c|c|}
\hline \multicolumn{2}{|c|}{ Component } & Quartz & Kaolinite & Muscovite & Calcite & Lepidocrocite \\
\hline \multicolumn{2}{|c|}{ Formula } & $\mathrm{SiO}_{2}$ & $\mathrm{Al}_{2} \mathrm{Si}_{2} \mathrm{O}_{5}(\mathrm{OH})_{4}$ & $\begin{array}{c}\mathrm{KAI}_{2}\left(\mathrm{AISi}_{3} \mathrm{O}_{10}\right) \\
(\mathrm{F}, \mathrm{OH})_{2}\end{array}$ & $\mathrm{CaCO}_{3}$ & $\mathrm{yFeO}(\mathrm{OH})$ \\
\hline \multirow{2}{*}{$\begin{array}{l}\stackrel{0}{\sigma} \\
\frac{D}{\mathbb{N}} \\
\frac{E}{2} \\
\frac{N}{\omega}\end{array}$} & FP & $1-200$ & $1-30$ & $1-50$ & $5-100$ & $1-50$ \\
\hline & PM10 & $1-10$ & $1-5$ & $1-5$ & $5-10$ & $1-10$ \\
\hline \multicolumn{2}{|c|}{ Color } & Green - gray & $\begin{array}{l}\text { White- } \\
\text { blue }\end{array}$ & Pink & Yellow-brown & $\begin{array}{l}\text { Reddish - } \\
\text { brown }\end{array}$ \\
\hline \multicolumn{2}{|c|}{ Shape } & round & tabular & tabular & round & elongated \\
\hline
\end{tabular}

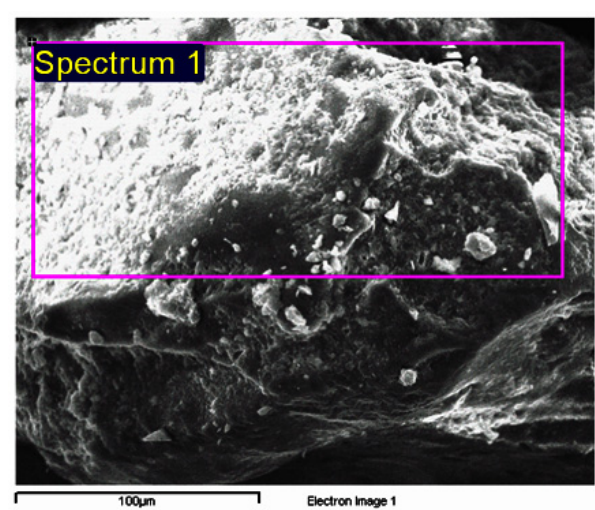

a

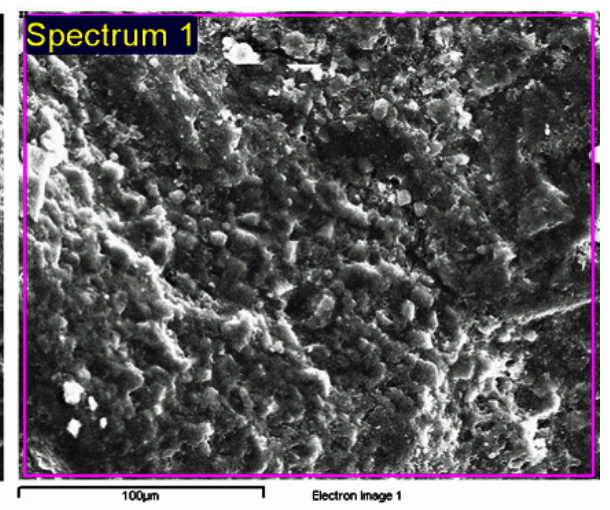

b

Figure 2. SEM images for particulate matter: a) FP and b) PM 10.

Clays, kaolinite and muscovite, are more often found as small fractions in airborne particles (e.g. PM10). A plenty of small clay platelet appear in PM10 sample, Figure 2b, which is in good agreement with high amount of $\mathrm{Al}, \mathrm{Na}$, and $\mathrm{K}$ observed for PM10 than in FP.

The large amount of quartz and silicates is supported by EDX spectrometry, the data in Table 3, where $\mathrm{Si}$ is one of the dominant elements.

Calcium amount is more representative for FP sample than for PM10, Table 3, confirming the optical microscopy observation that calcite is often found in FP as big particles than in PM10. Even small particles of calcite appear they have a great coalescence tendency forming clusters.

Traces of lepidocrocite observed in airborne particles are mainly related to transport activities rather than soil decay [6, 9]. The amount of $\mathrm{Fe}$ observed in Table 3 is in good agreement with the XRD observations. 
Table 3. Elemental composition for FP and PM10 resulted from EDX

\begin{tabular}{|c|c|c|c|c|}
\hline \multirow{2}{*}{ Element } & \multicolumn{2}{|c|}{ FP } & \multicolumn{2}{c|}{ PM10 } \\
\cline { 2 - 5 } & weight \% & atomic \% & weight \% & atomic \% \\
\hline $\mathrm{C}$ & 28.17 & 37.25 & 14.74 & 21.67 \\
\hline $\mathrm{O}$ & 52.52 & 52.13 & 52.12 & 57.55 \\
\hline $\mathrm{Na}$ & - & - & 2.97 & 2.29 \\
\hline $\mathrm{Al}$ & 1.37 & 0.81 & 5.01 & 3.28 \\
\hline $\mathrm{Si}$ & 15.42 & 8.72 & 22.33 & 14.05 \\
\hline $\mathrm{K}$ & 0.21 & 0.09 & 1.10 & 0.50 \\
\hline $\mathrm{Ca}$ & 1.16 & 0.46 & 0.99 & 0.43 \\
\hline $\mathrm{Fe}$ & 0.57 & 0.16 & 0.74 & 0.23 \\
\hline $\mathrm{Mg}$ & 0.58 & 0.38 & - & - \\
\hline $\mathrm{Total}$ & 100.00 & 100.00 & 100.00 & 100.00 \\
\hline
\end{tabular}

Inhalation of PM10 could be very harmful to the living organism, especially to long-term exposure. In vivo experiment was performed to observe the capacity of the nose mucosa to capture such mineral particles. The obtained results are shown in Figure 3.

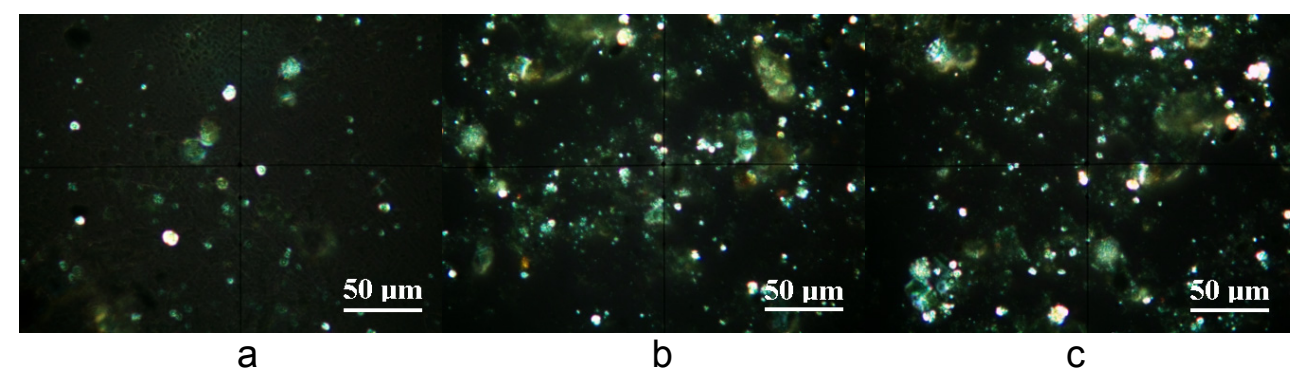

Figure 3. Nose exudates at different exposure times: a) 1 minute, b) 3 minutes and c) 10 minutes.

Exposure was performed under conditions with an FP of $26.4 \mathrm{~g} / \mathrm{m}^{2} / \mathrm{month}$ and $45.32 \mu \mathrm{g} / \mathrm{m}^{3}$ of PM10, respectively. Several quartz and clay particles are trapped in the nose exudates at 1 minute of continuous exposure, Figure $3 a$. Their dimensions are in the PM10 range. Their number is significantly increased, and some clusters are formed at 3 minutes of exposure, Figure $3 b$. Some FP particles are observed along with many PM10 at 10 minutes of exposure, Figure 3c.

The in vivo test demonstrates the ability of PM10 to enter into the respiratory system, the risk increasing with exposure time. It also proves that the nose mucosa is efficient for particulate matter PM10 and larger particles trapped to prevent the penetration of airborne particles into the lower respiratory system. 


\section{A. CHERECHES, I. PETEAN, G.-A. PALTINEAN, A. MOCANU, L. MURESAN, G. ARGHIR, M. TOMOAIA-COTISEL}

\section{CONCLUSIONS}

The air quality monitoring in Dej city generally shows a normal state of particulate matter emissions with average values below of standard limit in April and May 2017. Large amounts of mineral fractions were found, containing: quartz, calcite, clays (e.g. kaolinite and muscovite), and lepidocrocite. Their size varies in a wide range: from 1 to $200 \mu \mathrm{m}$ for floating particles and from 1 to $10 \mu \mathrm{m}$ for PM10 as observed by optical microscopy and SEM. The in vivo test shows the ability of PM10 to penetrate into upper respiratory tract. Mineral fractions were found in nasal exudates. At shorter time of exposure (e.g., 1 minute) only PM10 particles were observed. Greater particles than PM10 were found in nasal exudates at prolonged exposure of 3 minutes. To prevent lungs exposure to airborne particles, the nasal breathing is recommended instead of inhalation by mouth.

\section{EXPERIMENTAL SECTION}

The experimental zone is located in the city of Dej (Cluj county), near Vasile Alecsandri street. FP and PM10 were collected by the CJ-5 Automatic Air Monitoring Station at the Environmental Protection Agency in Cluj County, and the emissions in the atmosphere were monitored in April and May 2017 and the results were centralized.

X-ray diffraction analysis was performed on a DRON 3 diffractometer equipped with the MATMEC VI.0 data acquisition and software acquisition module. A monochrome $\mathrm{CO}_{\mathrm{k} \alpha}$ radiation was used for all $\mathrm{X}$-ray spectra. Mineral identification was performed using the standard MATCH 1.0 X - ray standard data base from Crystal Impact Co.

Optical microscopy was performed on a Laboval 2 microscope produced by Karl Zeiss Jena equipped with a Kodak $10 \mathrm{Mpx}$ digital camera. Quantitative analysis of optical micro-photographic images was done using the Image $\mathrm{J}$ professional software as a freeware resource from the National Institutes of Health, USA.

SEM images associated with EDX spectra were performed on a Jeol JSM 5600 LV microscope in the secondary electron imaging mode coupled with the Everhart Thornley detector for EDX analysis.

\section{REFERENCES}

1. A. Szakacs, Z. Pecskay, L. Silye, K. Balogh, D. Vlad, A. Fulop, Geologica Carphatica, 2012, 63(2), 139.

2. A. Codrea, O. Barbu, V. Codrea, Contributii Botanice, 2007, 62, 111. 
3. M. Alexe, Gh. Serban, A. Baricz, A.-S. Andrei, A. Cristea, K. P. Battes, M. Cimpean, L. Momeu, V. Muntean, S. A. Porav, H. L. Banciu, Joumal of Limnology, 2018, 77(1), 17.

4. S. Janhall, Atmospheric Environment, 2015, 105, 130.

5. A. Przybysz, A. Saebo, H. M. Hanslin, S. W. Gawronski, Science of the Total Environment, 2014, 481, 360.

6. K. V. Abhijith, P. Kumar, J. Gallagher, A. McNabola, R. Baldauf, F. Pilla, B. Broderick, S. Di Sabatino, B. Pulvirenti, Atmospheric Environment, 2017, 162, 71.

7. A. Talbi, Y. Kerchich, R. Kerbachi, M. Boughedaoui, Environmental Pollution, 2018, 232, 252.

8. W. Hu, H. Niu, K. Murata, Z. Wu, M. Hu, T. Kojima, D. Zhang, Atmospheric Environment, 2018, 179, 201.

9. D. F. Muntean, D. Ristoiu, G. Arghir, R. F. Campean, I. Petean, Carpathian Journal of Earth and Environmental Sciences, 2012, 7(3), 175.

10. R. F. Câmpean, I. Petean, M. Bărăian, G. A. Hosu-Prack, D. Ristoiu, G. Arghir, Carpathian Journal of Earth and Environmental Sciences, 2012, 7(2), 57.

11. T. Moreno, T. P. Jones, R. J. Richards, Science of the Total Environment, 2004, 334-335, 337.

12. P. Dagsson-Waldhauserova, O. Arnalds, H. Olafsson, Atmospheric Environment, 2013, 77, 117.

13. M. Lage, H. Lopes, M. da S. Carvalho, Journal of Computational Physics, 2011, 230, 7736.

14. E. Kellner, J. A. Hubbart, Science of the Total Environment, 2018, 615, 1164.

15. E. C. Schiopu, Analele Universitatii Constantin Brancusi din Targu Jiu, Seria Inginerie, 2010, 3, 516.

16. S. H. Tan, M. Roth, E. Velasco, Atmospheric Environment, 2017, 170, 245.

17. D. Edelin, P.-C. Czujko, C. Castelain, C. Josset, F. Fayolle, Experimental Thermal and Fluid Science, 2015, 68, 634.

18. European Council, 2008. Directive 2008/50 of UE Parliament and European Council concerning atmosphere quality and a more clean atmosphere in Europe, 2008. Official Journal of European Union, RO: L152, 1 - 44.

19. T. Banerjee, R. A. Christian, Atmospheric Pollution Research, 2018, 9, 342.

20. L. Calderon-Garciduenas, A. Calderon-Garciduenas, R. Torres-Jardon, J. Avila-Ramirez, R. J. Kulesza, A. D. Angiulli, Primary Health Care Research \& Development, 2015, $16,329$.

21. L. Megido, B. Suarez-Pena, L. Negral, L. Castrillon, S. Suarez, Y. Fernandez-Nava, E. Maranon, Chemosphere, 2016, 162, 73.

22. S. Catino, M. Tutino, S. Ruggieri, C. Marinaccio, R. Giua, G. De Gennaro, P. Corsi, G. Assennato, D. Ribatti, Ecotoxicology and Environmental Safety, 2017, 140, 156.

23. C. Wen, M. Xu, D. Yu, C. Sheng, H. Wu, P. Zhang, Y. Qiao, H. Yao, Proceedings of the Combustion Institute, 2013, 34(2), 2383.

24. L. Makra, I. Ionel, Z. Csépe, I. Matyasovszky, N. Lontis, F. Popescu, Z. Sümeghy, Science of the Total Environment, 2013, 458-460, 36.

25. M. Diociaiuti, M. Balduzzi, B. De Berardis, G. Cattani, G. Stacchini, G. Ziemacki, A. Marconi, L. Paoletti, Environmental Research Section A, 2001, 86(3), 254.

26. C. Capatina, C. M. Simonescu, N. Dadalau, D. Cirtina, Revista de Chimie, 2016, 67(7), 1247. 


\section{A. CHERECHES, I. PETEAN, G.-A. PALTINEAN, A. MOCANU, L. MURESAN, G. ARGHIR, M. TOMOAIA-COTISEL}

27. G. A. Paltinean, I. Petean, G. Arghir, D. F. Muntean, M. Tomoaia-Cotisel, Revista de Chimie, 2016, 67(6), 1118.

28. G. A. Paltinean, I. Petean, G. Arghir, D. F. Muntean, L. Muresan, M. TomoaiaCotisel, Annals of the Academy of Romanian Scientists Series on Physics and Chemistry Sciences, 2017, 2(2), 43.

29. G. A. Hosu-Prack, I. Petean, G. Arghir, L.D. Bobos, M. Tomoaia-Cotisel, Studia, Universitatis Babeş-Bolyai, Chemia, 2010, 55(3), 93.

30. I. Petean, A. Mocanu, G. A. Paltinean, R. Tarcan, D. F. Muntean, L. Muresan, G. Arghir, M. Tomoaia-Cotisel, Studia Universitatis Babes-Bolyai Chemia, 2017, 62(4), Tom I, 33.

31. L. Zhang, Y. Ninomiya, T. Yamashita, Fuel, 2006, 85(10-11), 1446.

32. I. Petean, G. A. Paltinean, A. Mocanu, D. F. Muntean, L. Muresan, G. Arghir, M. Tomoaia-Cotisel, Studia, Universitatis Babeş-Bolyai Chemia, 2018, 63(3), 49.

33. G. A. Hosu-Prack, I. Petean, G. Arghir, L.D. Bobos, M. Tomoaia-Cotisel, Carpathian Journal of Earth and Environmental Sciences, 2016, 11(2), 539.

34. G. A. Paltinean, I. Petean, G. Arghir, D. F. Muntean, L.D. Bobos, M. TomoaiaCotisel, Particulate Science and Technology: An International Journal, 2016, 34(5), 580.

35. S. Rapuntean, R. Balint, G. A. Paltinean, Gh. Tomoaia, A. Mocanu, Cs. P. Racz, O. Horovitz, M. Tomoaia-Cotisel, Studia Universitatis Babeş-Bolyai Chemia, 2018, 63(3), 73.

36. O. Cadar, P. T. Frangopol, Gh. Tomoaia, D. Oltean, G. A. Paltinean, A. Mocanu, O. Horovitz, M. Tomoaia-Cotisel, Studia Universitatis Babeş-Bolyai Chemia, 2017, 62(4), Tom I, 67.

37. M. Tomoaia-Cotisel, A. Tomoaia-Cotisel, T. Yupsanis, Gh. Tomoaia, I. Balea, A. Mocanu, Cs. Racz, Revue Roumaine de Chimie, 2006, 51 (12),1181.

38. Gh. Tomoaia, P.T. Frangopol, O. Horovitz, L.D. Bobos, A. Mocanu, M. Tomoaia-Cotisel, Journal of Nanoscience and Nanotechnology, 2011, 11 (9), 7762.

39. Gh. Tomoaia, L.B. Pop, I. Petean, M. Tomoaia-Cotisel, Materiale Plastice, 2012, 49 (1), 48.

40. R.D. Pasca, A. Mocanu, S.C. Cobzac, I. Petean, O. Horovitz, M. Tomoaia-Cotisel, Particulate Science and Technology: An International Journal, 2014, 32(2), 131.

41. B. J. Lee, B. Kim, K. Lee, Toxicological Research, 2014, 30(2), 71.

42. S. C. Fang, A. Cassidy, D. C. Christiani, International Journal of Environmental Research and Public Health, 2010, 7, 1773.

43. T. N. Perkins, P. M. Peeters, C. Albrecht, R. P. F. Schins, M. A. Dentener, B. T. Mossman, E. F. M. Wouters, N. L. Reynaert, Toxicology and Applied Pharmacology, 2018, 348, 43.

44. R. G. Lucchini, D. C. Dorman, A. Elder, B. Veronesi, Neuro Toxicology, 2012, 33, 838. 